\title{
New editions and new titles to read by the fire
}

\section{Compiled by Helen Nield}

To borrow any of these titles please email library@bda.org or call 0207563 4545. Although BDA members are responsible for return postage costs, books are sent out to them free of charge. They may be kept for at least four weeks and can be renewed if not requested by others.

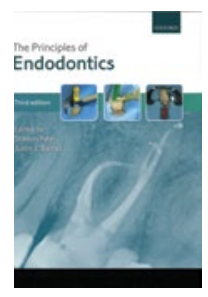

THE PRINCIPLES OF ENDODONTICS (3RD EDITION)

Shanon Patel and Justin J Barnes (Editors) 2019; Oxford University Press; 216 pp; paperback ISBN: 9780198812074

'Patients with endodontic disease may present in a variety of ways, ranging from being completely symptom-free, to presenting with severe orofacial pain and swelling.

This is a very welcome new edition. Initially due out in the summer it has only just been published. In a deceptively slim, A4 size a large amount of information has been tucked away with the aim of providing a 'contemporary comprehensive guide to endodontics'. There have been significant revisions and updates of both text and illustrations since the 2013 edition including new sections on iatrogenic endodontic infection and data protection. In addition, new troubleshooting and self-assessment multiple choice sections have been added. Contributors include Len D'Cruz, who has written a chapter on the dento-legal aspects of endodontics, Avijit Banerjee, Bhavin Bhuva, Edward Brady, Francesco Mannocci and others.

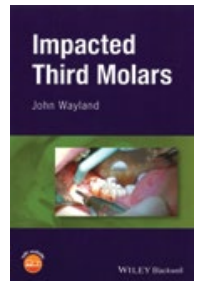

\section{IMPACTED THIRD MOLARS \\ John Wayland}

2019; John Wiley \& Sons Ltd; 280 pp; hardback ISBN: 9781119118336

'Fear of the unknown is a common barrier preventing dentists from removing third molars. They often ask themselves, "Is this third molar too close to the inferior alveolar nerve?" "How much bleeding is normal?" "What should I do if there's infection?"

This American title covers the tricky subject of third molar surgery. It has been written 'for general dentists who like to predictably, safely and efficiently remove impacted third molars', and is full of practical and useful information that can be used in general dental practice. The contents cover anatomy, case selection, complications, work space (equipment, instruments and materials), surgical principles and techniques, pharmacology, sedation techniques, sedation emergencies and monitoring, documentation and the author's own 'mobile third molar practice' in the San Francisco Bay Area in California. Since this is a US publication the documentation chapter and some of the procedures will not be transferrable to a UK practice. Nevertheless, this is still a useful addition to the sparse body of literature on the practicalities of third molar surgery. This book can be purchased from the library's ebook collection on request.

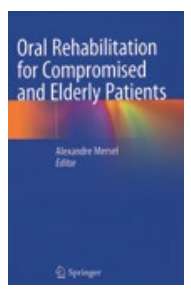

\section{ORAL REHABILITATION FOR COMPROMISED AND ELDERLY PATIENTS}

Alexandre Mersel (Editor) 2019; Springer Nature; 196 pp; hardback ISBN: 9783319761282

'The elderly patient is a frail patient; any intervention could lead to a psychological or medical collapse. During treatment it is essential to maintain balance and in this way provide a good quality of life. Therefore, a new bioethical approach should be introduced into basic and continuing education programs. The publication of this book is an essential step.'

According to Douglas Berkey from the University of Colorado who wrote one of the forewords for this book it is 'directed toward teaching dentists how they can better provide evidence-based dental treatment for their aging patients'. Alexandre Mersel has written three of the chapters but the remaining eight have all been authored by other specialists from a variety of different countries. Chapters cover, amongst other topics: systemic diseases and oral health, the treatment of periodontal diseases, physiological changes in endodontics, TMJ disorders, masticatory function and nutritional status, carious destruction of the remaining teeth and prosthetic techniques and choices. The author believes that a number of widely held beliefs and practices in prosthetic dentistry have no evidencebase when it comes to the elderly: 'there is no evidence-based correlation between the quality of the prosthetic and the satisfaction of the patients'. This book challenges assumptions and looks at new strategies in combination with patient satisfaction. It can also be read as part of the library's ebook collection - www.bda.org/ebooks.

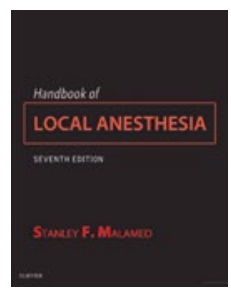

\section{HANDBOOK OF LOCAL ANESTHESIA} (7TH EDITION)

Stanley Malamed

2019; Elsevier Mosby; 464 pp.; paperback ISBN: 9780323582070

'Although the drugs remain the same ... the years since the sixth edition have seen the introduction and refinement of drugs and devices that work to help the dental profession come ever closer to the twin goals of truly pain-free dentistry and truly pain-free local anesthetic injections.'

One of the few seminal textbooks that is still almost wholly authored by one man, the new edition of this American title has been significantly updated in many places. It retains the same four sections on Drugs, The Armamentarium, Techniques of Regional 


\section{BDA Update}

1 Anesthesia in Dentistry and Complications, Legal Considerations, Questions, and the Future. However, two completely new chapters have been introduced into the final section of the book. The new Chapter 19 covering problems in achieving pain control has been added because one of the author's most frequently asked questions is about how to consistently achieve effective pulpal anaesthesia with teeth that are acutely pulpally involved. In the new Chapter 20, Malamed explores five fairly new additions to 'the pain control armamentarium in dentistry' that he feels will stand the test of time. This book can be purchased for the library's ebook collection on request.

\section{View from my window}

Duncan Parker-Groves sent this view from his dental surgery.

Duncan writes: 'I am currently serving as part of an exchange programme in Brunei Darussalam, the Abode of Peace, alongside the RBAF as a dental officer.

'This is the fantastic view from my dental surgery at the Berakas Kem (RBAF land forces camp). I am fortunate to look out over the golf course and I am frequently visited at my window by wild boars and macaque monkeys. The monkeys take a particular interest in extractions! If you look carefully you can see a monkey walking off.'

If you would like to send the view from your practice window, please email k.quinlan@nature.com.

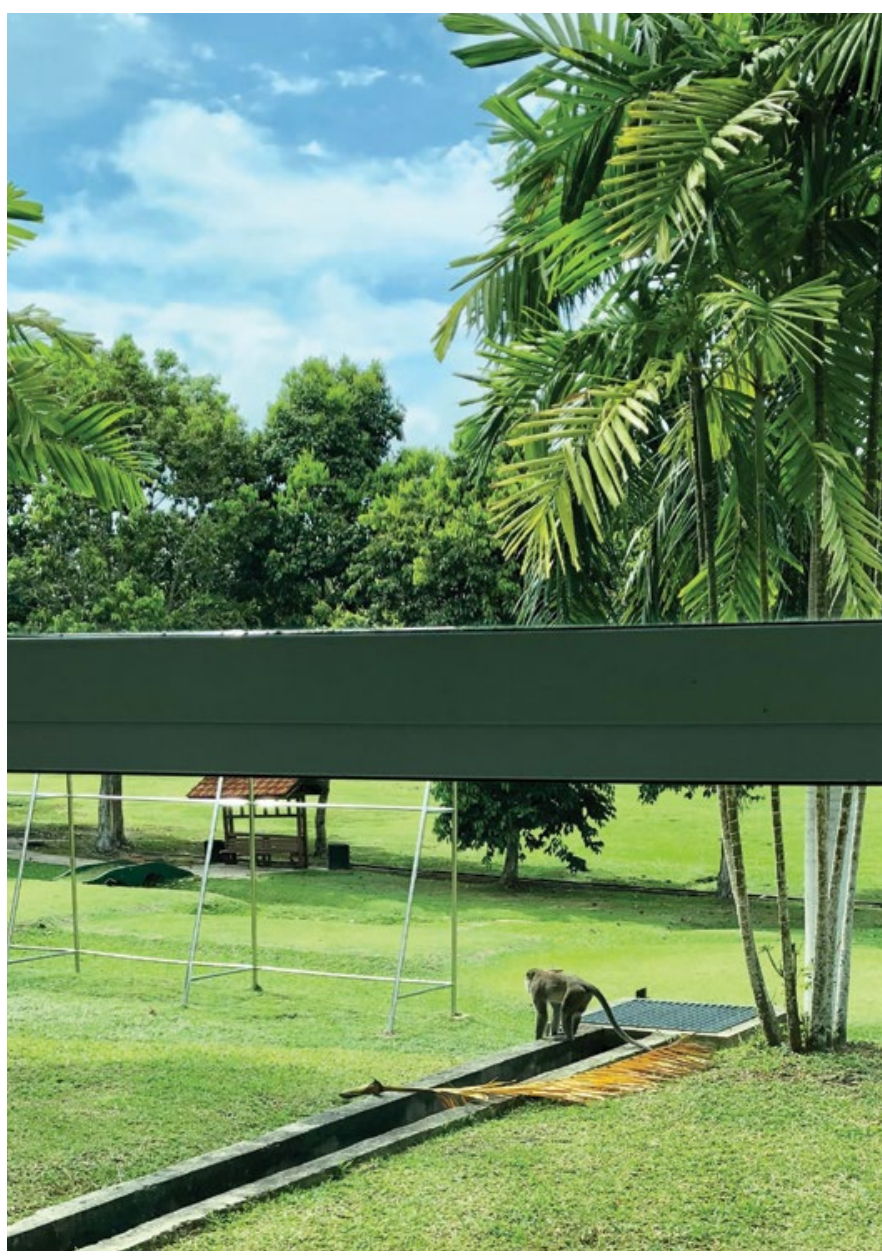

\section{Apps no quick fix}

The BDA has expressed scepticism over the role of teleconsultations in dentistry, following the launch of the new app Tooth Fairy.

The BDA recognises the potential for this technology in areas including triaging cases for NHS 111, but does not see how it is possible to conduct a full and thorough examination remotely on the basis of current technology.

\section{Oral surgery scandal}

BDA Scotland has said government must take responsibility and tackle waiting times of over two years for oral surgery.

Freedom of Information requests undertaken by the Scottish Liberal Democrats have revealed waits of over 120 weeks (2.3 years) for inpatient oral and maxillofacial treatment, covering diseases affecting the mouth, jaw, face and neck - with one patient in the NHS Grampian area having waited 243 weeks (4.6 years) for an outpatient procedure. The Scottish Government operates a 12 -week target for surgery.

These figures include procedures that can restore the functionality and appearance of a patient's mouth following oral cancer - which ranks among Scotland's fastest growing cancers - or serious injury.

There have been huge problems filling consultant vacancies and continued underfunding of both primary and secondary dental services.

\section{Delayed pay rise}

In October the BDA received confirmation that dentists will get a $2.42 \%$ uplift in their November pay run. The Department of Health and Social Care (DHSC) and HM Treasure calculated the formula using the consumer price index for inflation, not the retail price index for inflation, as argued by the BDA.

The DHSC confirmed that the uplift for 2019/2020 will be backdated to April 2019. The BDA questions why implementing the dentists' award continues to lag so many months behind, when practitioners are obliged to pay their bills in a timely fashion.

\section{Are you a dental expert?}

The dental expert plays a pivotal role and is essential to the defence of a dental colleague faced, for example, with a GDC fitness to practise hearing or who finds themselves subject to a claim in negligence.

BDA Indemnity is now looking to expand the dental experts that they can call on, covering the whole spectrum of dental practice, to help the rapidly growing number of BDA Indemnity members that have been joining since our inception date of 3 June 2019.

We are looking for experts who have current experience of doing this type of work, with knowledge of expert report writing and being prepared potentially for cross examination in court procedures.

If you are interested in this unique opportunity to work in this niche area of dentistry to help your professional colleagues, then please send in your current $\mathrm{CV}$ on a confidential basis by the closing date of 31 December 2019 to be considered for this vital role for BDA Indemnity members. Please send to bda.indemnity@bda.org. 